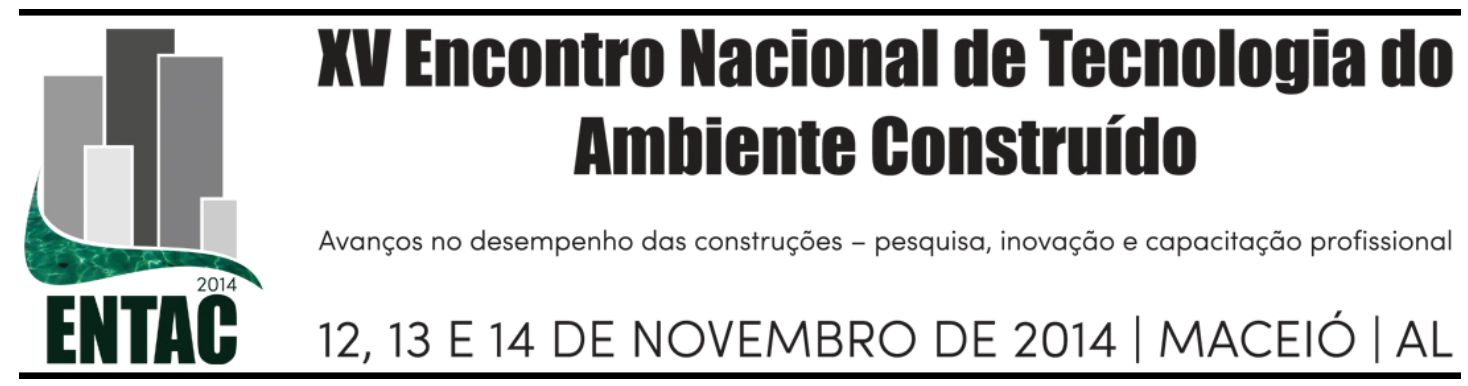

\title{
TIPOLOGIA, TOPOLOGIA E FUNCIONALIDADE NOS PROJETOS ARQUITETÔNICOS DO PROGRAMA DE ARRENDAMENTO RESIDENCIAL EM MACEIÓ-AL
}

\author{
PORANGABA, Alexsandro Tenório
}

Universidade Federal de Sergipe, e-mail: soualex@hotmail.com

\begin{abstract}
RESUMO
O objetivo deste trabalho ${ }^{1}$ é analisar a organização funcional, a geometria dos cômodos, identificar tipologias de edifícios e analisar as relações topológicas existente nos projetos arquitetônicos de 21 edifícios do Programa de Arrendamento Residencial (PAR) em Maceió-AL, fundamentadas nos estudos desenvolvidos por Hillier e Hanson (1984), Schneider (1998) e Brandão (2006). As análises evidenciaram que o tradicional modo tripartido de habitação (social, íntimo e serviço) é significativamente presente, bem como as geometrias mais recorrentes nos cômodos foram: formato quadrado, retangular, "L" e o "T". Identificaram três tipos arquitetônicos: (1) blocos em formato "H"; (2) com caixa inserida; e (3) com caixa de escada e circulação externa. As relações topológicas evidenciaram que nos projetos pertencentes ao tipo 1 , o hall de circulação interna é uma elemento importante de conexão entre os cômodos, já nos projetos caracterizados como tipo 2 e 3, a sala de estar e jantar funciona como cômodo de distribuição para os demais setores. Portanto, soluções projetuais cuja inserção de halls de distribuição não seja considerada, favorecem a redução de área útil no cômodo e ainda podem apresentar problemas relacionados à perda de privacidade. Assim, espera-se que essa pesquisa possa contribuir para a produção de projetos habitacionais com qualidade funcional, sobretudo os submetidos a programas habitacionais voltados a população de menor poder aquisitivo.
\end{abstract}

Palavras-chave: Tipologia, Topologia, Programa de Arrendamento Residencial.

\begin{abstract}
The objective of this work is to analyze the functional organization, the geometry of the rooms, identify types of buildings and analyzing the topological relationships existing in the architectural designs of the 21 buildings Residential Leasing Program (PAR) in Maceio-AL, based on the studies developed by Hillier and Hanson (1984), Schneider (1998) and Brandão (2006). The analyzes showed that the traditional mode tripartite housing (social, intimate and service) is significantly present as well as the most recurring geometries in the rooms were square shaped, rectangular, " $L$ " and " $T$ ". Architectural identified three types: (1) block "H" format; (2) with inset box; and (3) with ladder and external circulation box. The topological relations showed that the projects belonging to type 1, the hall of internal circulation is an important element of connection between the rooms, since the projects characterized as type 2 and 3, the living room and dining room serves as a distribution to other sectors. Therefore, design solutions whose insertion halls distribution is not considered, favoring the reduction of floor space in the room and can still present problems related to loss of privacy. Thus, it is expected that this research will contribute to the production of housing projects with functional quality, especially those undergoing housing programs aimed at people with less purchasing power.
\end{abstract}

Keywords: Typology, topology, Residential Leasing Program.

\footnotetext{
${ }^{1}$ Este trabalho é resultante da pesquisa concluída em nível de mestrado em Arquitetura e Urbanismo DEHA/UFAL financiada pela FAPEAL sob orientação do Professor Dr. Alexandre Márcio Toledo.
} 


\section{INTRODUÇÃO}

\subsection{O PAR no Estado de Alagoas}

Ao ser instituído pela medida provisória n.1.823 em 1999 (MINISTÉRIO DAS CIDADES, 1999), a produção de habitações pelo Programa de Arrendamento Residencial (PAR) se difundiu pelo Brasil de forma expressiva. No Estado de Alagoas, priorizou-se inicialmente a construção de unidades habitacionais na capital Maceió, sendo que a maior parte delas caracterizadas como sendo PAR-1. Somente em 2006 é que as habitações mínimas, caracterizadas como PAR-2, são implementadas na capital ${ }^{2}$. Até o ano de 2009, construíram-se em Alagoas 8.556 unidades habitacionais, sendo 8.140 em Maceió (CAIXA, 2009). Os números ora citados demonstram o quanto o PAR desempenhou papel importante no combate ao déficit habitacional no Estado de Alagoas.

\subsection{Noção de Tipologia e Topologia}

Para Aymonino (apud MONTANER, 2001), tipologia é entendida como um instrumento e não como uma categoria, é um método de análise de projeto que envolve a relação entre o todo e as partes da unidade construtiva. Tratando-se de análise tipológica de habitações coletivas ou multifamiliares, Brandão e Heineck (2004, p. 2776) afirmam que consideram-se nas análises, "a forma geral do apartamento, circulação interna, além de critérios de distribuição e interconexão". Além desses aspectos, é possível, segundo os autores, analisar a tipologia de um apartamento observando na planta o seu conteúdo programático (cômodos existentes, número de dormitórios e banheiros, dentre outros).

Contudo, a literatura apresenta um rol diversificado de partidos arquitetônicos, referente a plantas de apartamentos, destaca-se como interessante a classificação tipológica realizada por Schneider (1998), que distinguiu oito tipologias de plantas de apartamentos, exclusivamente de edifícios residenciais, observando sua organização espacial e formas de articulação, determinando, deste modo, as seguintes categorias: plantas tipo corredor, caixa inserida, com sala de estar central, com separação das áreas funcionais, orgânica, fluida, flexível e circuito.

Além do estudo tipológico, uma planta arquitetônica pode evidenciar as relações topológicas de modo a deixar transparecer os aspectos funcionais presentes no projeto. A topologia tem sido encontrada segundo certas recorrências temáticas em procedimentos projetuais, sobretudo nas investigações de obras da arquitetura contemporânea, sobretudo no estudo das propriedades geométricas e não de suas características formais. Sperling (2008, p. 40) ressalta que "interessa à Topologia menos a forma, que estaria vinculada à topografia e mais as relações existentes entre os pontos desta forma $[\ldots] "$ ".

As pesquisas acerca das articulações espaciais em arquitetura com foco em aspectos topológicos centram-se nas relações espaciais invariantes, ou seja, depreendidas da forma ou das mutações formais de um projeto. Para o estudo dessas relações a topologia trata das proximidades, conectividades e continuidade entre os espaços possíveis de serem aplicados a qualquer ponto ou regiões de um objeto geométrico (SPERLING,

\footnotetext{
${ }^{2}$ Os projetos do PAR caracterizados como sendo PAR-1, possuem área útil mínima de $37 \mathrm{~m}^{2}$ e os do PAR-2, a área útil mínima é de $35 \mathrm{~m}^{2}$ (PAR-2) e 37 m² (PAR-1)
} 
2003, p. 129). Logo, a leitura espacial de um edifício pode ser desenvolvida por meio de conexões e articulações próprias da Teoria dos Grafos.

A tradução de uma planta arquitetônica para um grafo, compreendido como sendo a representação gráfica constituída de pontos e segmentos de retas, tem por finalidade a representação das interconexões espaciais estabelecidas no espaço arquitetônico. Assim sendo, de acordo com Hillier e Hanson (1998, p. 90) a planta arquitetônica pode ser apreendida por meio da construção de convex map (mapa convexo) e gamma map (mapas grafos ou grafos).

\section{METODOLOGIA}

O objetivo deste trabalho é analisar a organização funcional, a geometria dos cômodos, identificar tipologias de edifícios e analisar as relações topológicas existente nos projetos arquitetônicos de habitações verticais do Programa de Arrendamento Residencial (PAR) em Maceió-AL. Para tanto, selecionaram-se 21 projetos, sendo 15 do PAR-1 e 06 do PAR-2. As análises desenvolvidas são fundamentadas nos estudos de Hillier e Hanson (1984), Schneider (1998) e Brandão (2006). Cabe enfatizar que os estudos desenvolvidos pelos autores referenciados não tratam particularmente de Habitações de Interesse Social (HIS), deste modo, buscou-se adequar tais estudos em função do recorte tipológico: edifício residencial multifamiliar de Habitações de Interesse Social.

A apreensão da organização espacial das habitações do PAR transcorreu-se em duas etapas: na primeira etapa, identificaram-se: A organização funcional das unidades habitacionais em setores, social, íntimo e serviço; a geometria dos cômodos e o número de acessos às unidades habitacionais; na segunda etapa corresponde ao processo de classificação tipológica dos projetos dos PAR. Nesse processo, utilizou-se da noção de topologia, visto que essa contribui para a apreensão das interconexões existentes entre os cômodos da habitação.

Após a identificação dos setores funcionais, foi possível extrair desses os grafos justificados, com a aplicação do método dos grafos (HILLIER; HANSON, 1984). Tal representação iniciou-se com a construção dos mapas convexos e posterior grafos justificados.

\section{RESULTADOS}

Os projetos do PAR geralmente são divididos por um eixo central, marcado pela caixa de escada que possibilita o acesso a dois ou quatro apartamentos por pavimento; é frequente a aglutinação das áreas molhadas (cozinha, área de serviço e banheiro), ora nas extremidades laterais dos apartamentos, ora próximo da caixa de escada. Entretanto, algumas propostas não seguem à risca esse modo organizacional, segregando o banheiro dos demais cômodos molhados.

Com base na organização espacial, considerando os aspectos formais, os projetos analisados foram classificados em três tipos arquitetônicos (Figura 1): Tipo 01 (bloco em formato "H" com uma caixa de escada para cada duas ou quatro unidades habitacionais)

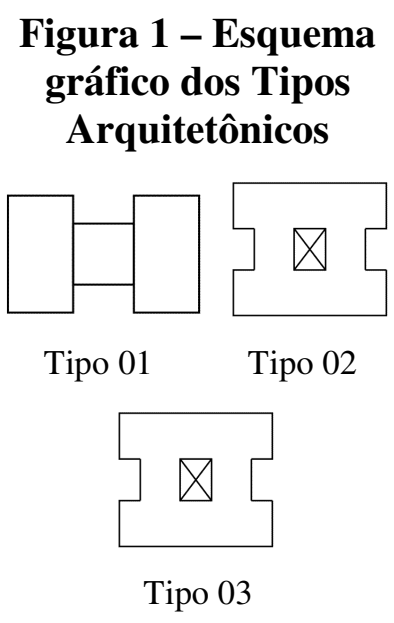

Fonte: Arquivo pessoal do autor 
é frequente em oito projetos do PAR-1 e nos seis do PAR-2. Tipo 02 (bloco com caixa inserida $^{3}$ e uma caixa de escada para cada duas unidades) é presente em seis projetos do PAR-1, sobretudo nos projetos conjugados dois a dois, ou seja, configurando um total de oito unidades habitacionais por pavimento. Tipo 03 (bloco com caixa de escada e circulação externa) é atribuído a um empreendimento do PAR-1. Esse tipo de organização priorizou a constituição de um pátio aberto com caixas de escada descobertas e localizadas em duas arestas opostas do edifício.

Seguindo o tradicional modelo burguês de habitação do século XIX, os projetos do PAR são tripartidamente divididos por: Setor Social (sala de estar e jantar), Setor Íntimo (quartos e banheiro) e Setor de Serviço (cozinha e área de serviço). Além da organização dos cômodos em setores funcionais, a maioria dos projetos possui uma área de transição composta pelo hall de circulação e pelo hall de entrada. Salienta-se que nem todos os projetos apresentam halls. Além da organização espacial das plantas, a geometria, ou seja, o formato dos cômodos também demarca a espacialização da habitação bem como o uso dos mesmos. Deste modo, as formas geométricas identificadas nos projetos arquitetônicos do PAR são:

- Formato quadrado destinado a ambientes como quartos e banheiros. Todavia, no caso dos banheiros, o mesmo não favorece a distribuição das peças sanitárias e há ocorrência de estreitamento do box devido à redução dimensional do cômodo. Algumas propostas optam por adotar o referido formato nos dois quartos, sem diferenciação dimensional, que do ponto de vista da flexibilidade é positivamente adequado, pois permite que o usuário defina em quais dos cômodos ficará para uso do casal ou solteiro duplo.

- Formato retangular usualmente aplicado em um dos quartos, sala estar/ jantar, hall de circulação e de entrada, banheiro, cozinha e área de serviço. Para a sala de estar e jantar, esse formato não evidencia a separação funcional das atividades a que se destina. Comumente, cozinha e área de serviço integram o mesmo formato geométrico, a distinção das funções, nesse caso, é demarcada pela instalação dos equipamentos, sobretudo, bancada da cozinha e tanque de lavar roupas.

- Formato "L" particularmente utilizado em quatro projetos, nos ambientes: sala de estar/jantar, cozinha e quartos. No Projeto 01 (Figura 2), o formato "L" é sutilmente evidenciado pelo deslocamento da janela da sala; entretanto, sua existência poderia ser ignorada, pois a largura e o comprimento do espaço deslocado não contribuem significativamente em termos funcionais com o ambiente. No Projeto 02 (Figura 3), o referido formato é evidenciado pelo deslocamento da parede onde se localiza a porta de entrada da sala de estar e jantar, bem como quartos. Já no Projeto 03 (Figura 4), a cozinha e a área de serviço são distintamente separadas e suas funções são evidenciadas em razão do formato geométrico empregado; além disso, a privacidade da área destinada à limpeza em relação à área de cozimento é potencializada. Além dos projetos supracitados, o formato "L" é presente também nos dois quartos do Projeto 04 (Figura 5), cuja função é a inserção de um armário embutido em uma das pontas do "L".

\footnotetext{
${ }^{3}$ A caixa inserida é um espaço central descoberto que serve como elemento facilitador na captação de vento e exaustão para as áreas molhadas: cozinha, área de serviço e banheiro.
} 
Figura 2 - Projeto 01: Planta Baixa Sala do Residencial Bernardo Oiticica

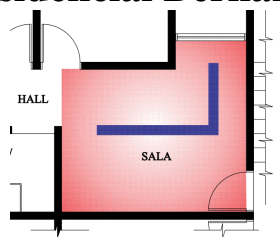

Fonte: Arquivo pessoal do autor

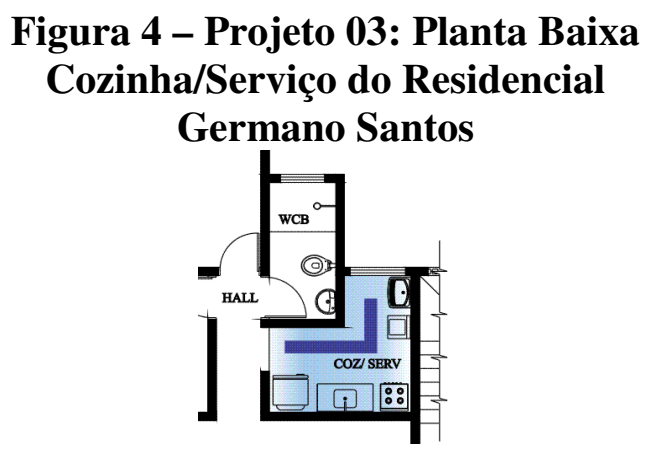

Fonte: Arquivo pessoal do autor
Figura 3 - Projeto 02: Planta Baixa Pav. Tipo do Residencial Ouro Preto I

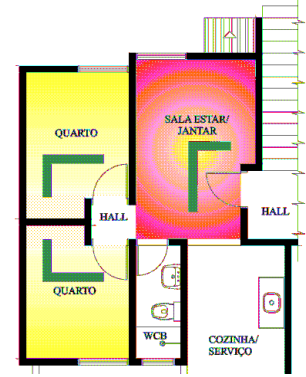

Fonte: Arquivo pessoal do autor

Figura 5 - Projeto 04: Planta Baixa Quartos do Residencial Costa Dourada

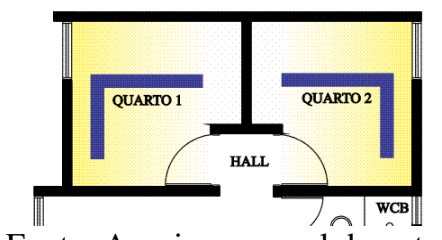

Fonte: Arquivo pessoal do autor

- Formato "T", esse formato está presente nos projetos dos Residenciais Praias Belas (Figura 6), Germano Santos (Figura 7) e Canto dos Pássaros (Figura 8), especificadamente na junção da sala com o hall de circulação. Essa junção segrega espacialmente a sala em dois compartimentos distintos e sem usos definidos. Deste modo, o formato "T" se apresenta como ponto positivo, pois não fixa rigidamente os usos do cômodo. Porém, o posicionamento do setor de serviço, aparenta sinalizar a localização da atividade de jantar em uma das extremidades do "T".

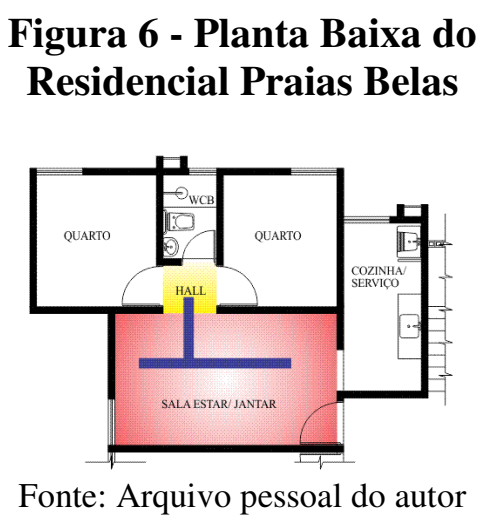

Figura 6 - Planta Baixa do

Fonte: Arquivo pessoal do autor

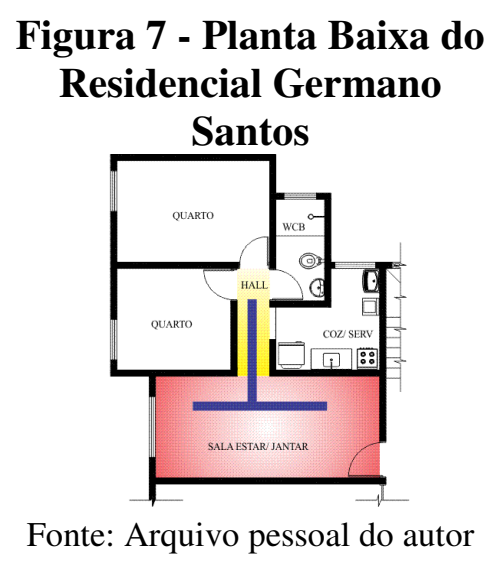

Figura 8 - Planta Baixa do Residencial Canto dos Pássaros

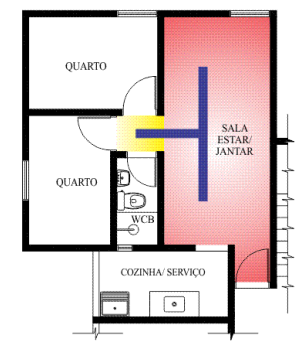

Fonte: Arquivo pessoal do autor

\subsection{Representação Topológica e Caracterização do Tipo 01}

Dentre os projetos arquitetônicos que estão inseridos na classificação tipológica 01 (blocos em formato "H"), um empreendimento do PAR-1 possui caixa de escada para duas unidades habitacionais. Os demais projetos, sete do PAR-1 e seis do PAR-2, são constituídos por uma caixa de escada para quatro apartamentos por pavimento que estabelecem relação de proximidade por meio de um hall comum de circulação. Os grafos resultantes da setorização das plantas baixas (Figuras 9) evidenciam que, em todos os casos, é comum o acesso ao setor íntimo transcorrer por meio de um hall de circulação interno, localizado próximo do setor social. Algumas derivações ocorrem 
exatamente no grafo 02 e 05 , quando um dos cômodos do setor íntimo é acessado direto do setor social.

Figura 9 - Grafos justificados para as plantas do tipo 01

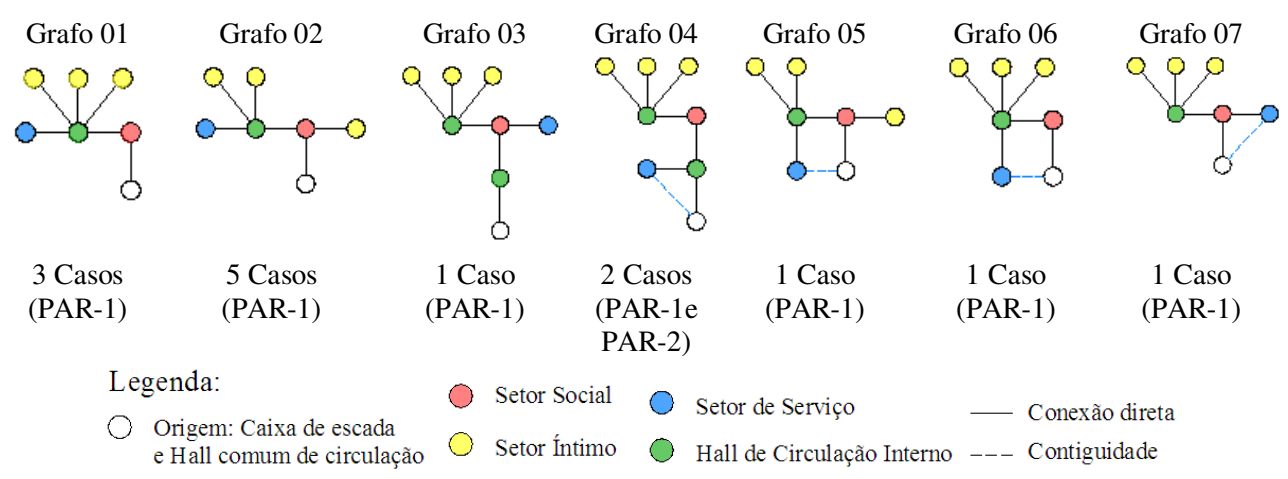

Fonte: Arquivo pessoal do autor

$\mathrm{Na}$ distribuição espacial dos cômodos, percebe-se nos grafos que o setor íntimo é comumente localizado nas extremidades dos projetos, possivelmente em razão da ventilação e iluminação. Além disso, o setor de serviço em cinco casos (grafos 04 a 07) estabelece relação de contiguidade com a caixa de escada e hall comum de circulação. Verifica-se ainda que apenas três casos inserem no projeto dois halls de circulação interna, especialmente nos grafos 03 e 04.

No Quadro 1, percebe-se que os projetos apresentam os setores íntimo e serviço com os mesmos formatos geométricos: um quarto quadrado e outro retangular; cozinha, área de serviço e banheiro em formato retangular. A diferença entre os projetos se encontra no formato geométrico do setor social, que no Bernardo Oiticica está em formato "L" e nos demais em formato retangular. Além da diferença geométrica do setor social, evidenciase que nos projetos dos Residenciais Mendonça Uchôa, Ouro Preto II e os correspondentes ao PAR-2, um dos quartos do setor íntimo, apresenta acesso direto pelo setor social.

\section{Quadro 1 - Representação Topológica dos Projetos Tipo 01: projetos com setor} social contíguo à caixa de escada e com um hall de circulação

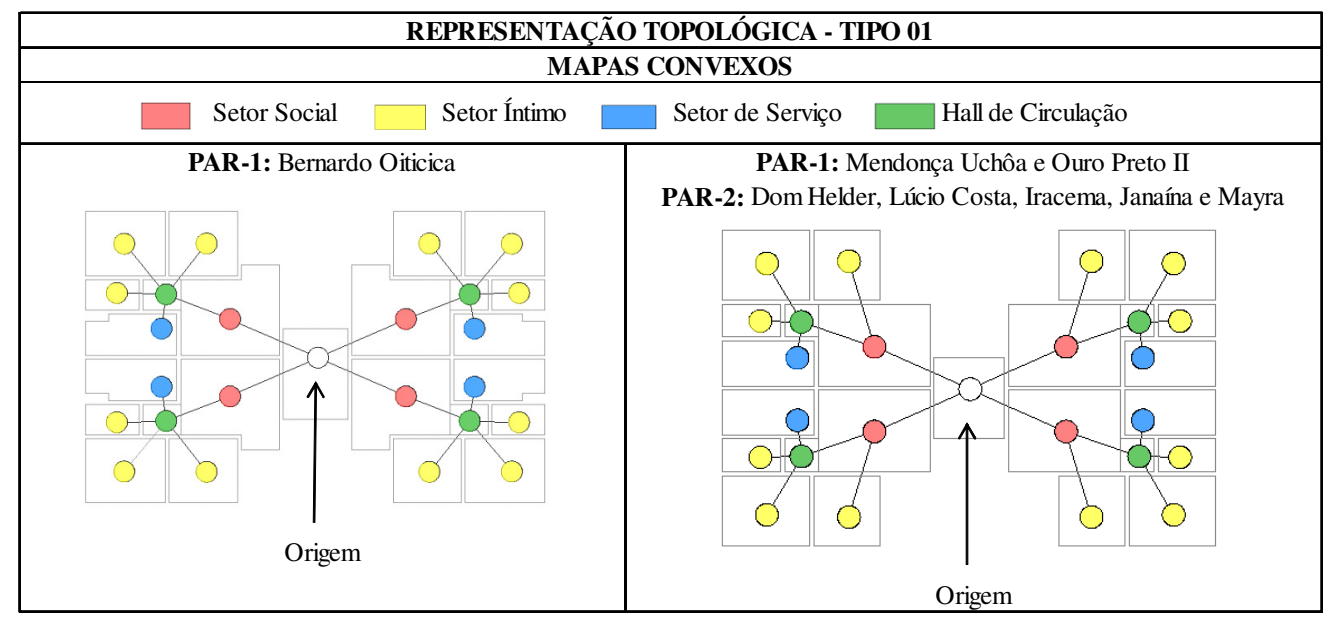

Fonte: Arquivo pessoal do autor

Além dos projetos supracitados, há os que são caracterizados pela existência de dois halls de circulação, sendo que um deles é localizado na entrada principal da habitação, considerado, deste modo, como sendo hall de entrada. Nesses, há predominância do formato retangular em quase todos os setores funcionais, com exceção dos quartos do Residencial Costa Dourada em formato "L" (Quadro 2). 
Nos projetos dos Residenciais Costa Dourada e Luiz dos Anjos, o setor de serviço é fortemente demarcado pela contiguidade junto a caixa de escada e hall comum de circulação; em ambos os casos, tal setor funcional possui ligação direta com o hall de entrada. Já no Residencial Canto dos Pássaros, o setor de serviço é acessado diretamente do setor social, mesmo possuindo um hall de entrada.

\section{Quadro 2 - Representação Topológica dos Projetos Tipo 01: projetos com dois halls de circulação}

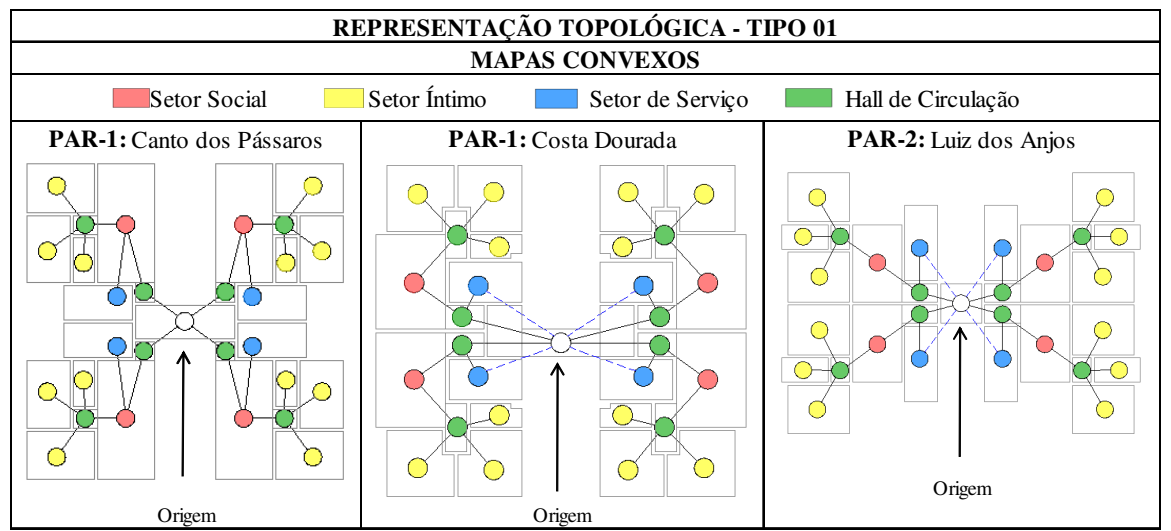

Fonte: Arquivo pessoal do autor

Verifica-se ainda a existência de projetos que possuem um hall de circulação e que a contiguidade com a caixa de escada é estabelecida pelo setor de serviço, neste caso, os projetos dos Residenciais Germano Santos, Praias Belas e Mata Atlântica (Quadro 3).

\section{Quadro 3 - Representação Topológica dos Projetos Tipo 01: projetos com setor de serviço contíguo à caixa de escada e com um hall de circulação}

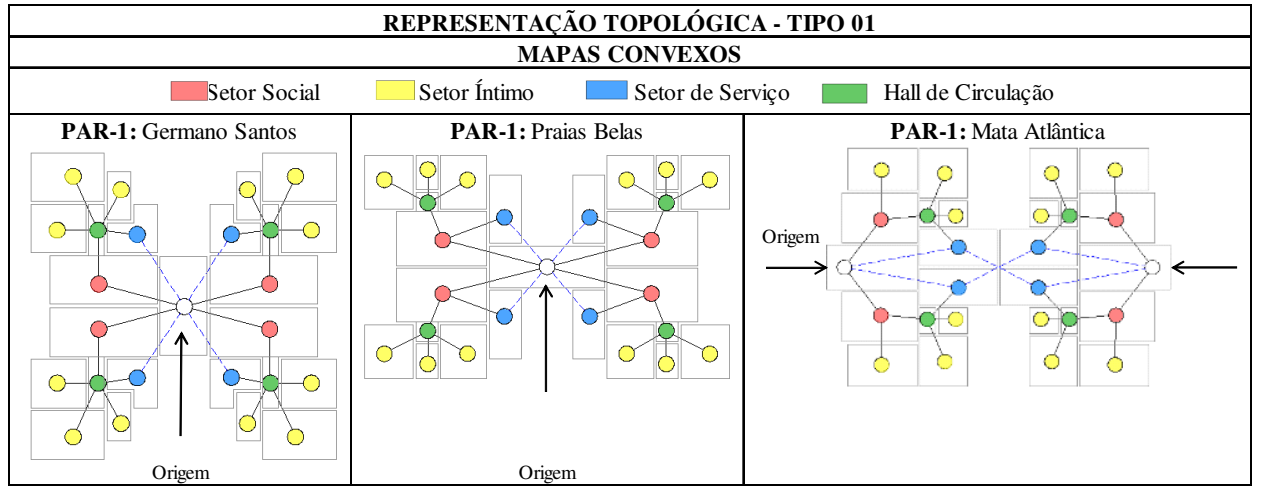

Fonte: Arquivo pessoal do autor

No projeto do Residencial Germano Santos, o modo como os setores íntimo e de serviço são organizados demarcam a distinção funcional do setor social (sala de estar e jantar) em duas extremidades, reforçada também pelo posicionamento do hall de circulação. Além dos formatos quadrados e retangulares comumente destinados aos setores social e íntimo, o setor de serviço do referido projeto possui o formato "L", cujas pontas extremas se destinam ao tratamento e preparo de alimentos e o de limpeza e manutenção da habitação. No projeto do Residencial Praias Belas, por não possuir um hall de entrada, o setor de serviço é acessado diretamente pelo setor social. Ademais, observase que o hall comum de circulação também sofreu aumento considerável de área.

Diferentemente dos demais projetos, o Residencial Mata Atlântica é o único exemplar em formato " $H$ " cuja caixa de escada possibilita o acesso a duas unidades habitacionais. Nesse, tanto o setor social quanto o setor de serviço são contíguos à caixa de escada, 
além disso, o setor social estabelece contato direto com um dos quartos e com o hall de circulação interno, responsável por interligar os demais cômodos da habitação.

\subsection{Representação Topológica e Caracterização do Tipo 02}

Os projetos caracterizados como tipo 02, apesar de possuírem uma caixa de escada para cada duas unidades, o pavimento tipo dos mesmos é composto por oito unidades habitacionais. Essas unidades mantêm relação de vizinhança tanto por meio do setor de serviço quanto por meio do setor íntimo (Figura 10).

Figura 10 - Grafos justificados para as plantas do tipo 02

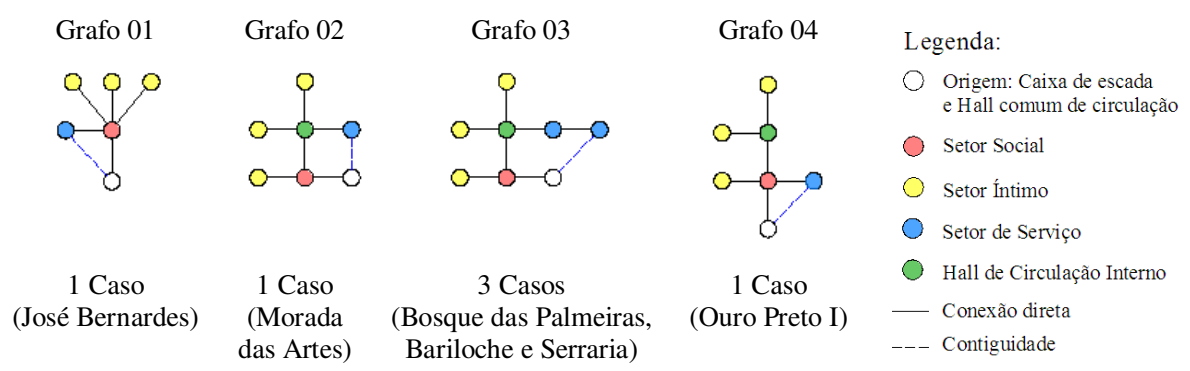

Fonte: Arquivo pessoal do autor

A primeira semelhança evidenciada por meios dos grafos entre os projetos é que o setor social e o setor íntimo são contíguos à caixa de escada e hall comum de circulação. Em cinco casos (grafos 02 a 04) o setor social se conecta a dois espaços distintos: o hall de circulação interno e um dos cômodos do setor íntimo. A exceção, nesse caso, relacionase com o grafo 01 cujos acessos aos setores, íntimo e de serviço, se estabelecem diretamente pelo setor social. Nesse caso, de acordo com Brandão (2006), projetos arquitetônicos que não contemplam corredores e/ou hall de circulação otimizam espaços e provavelmente elevam as vantagem econômicas em termos construtivos, mas, assumem o ônus de propiciar ao usuário perda de privacidade, justamente pelo fato dos cômodos íntimos serem abarcados visualmente da sala de estar/ jantar.

É comum nos projetos arquitetônicos o setor de serviço envolver as atividades da cozinha e da área de serviço num único cômodo. Entretanto, o grafo 03, semelhante ao grafo 02, difere-se desse último unicamente no setor de serviço. No grafo 03, o setor de serviço divide-se em dois cômodos distintos como é possível ver com detalhe no Quadro 4.

Quadro 4 - Representação Topológica dos Projetos Tipo 02: projeto dos Residenciais Morada das Artes, Bariloche Bosque das Palmeiras e Serraria

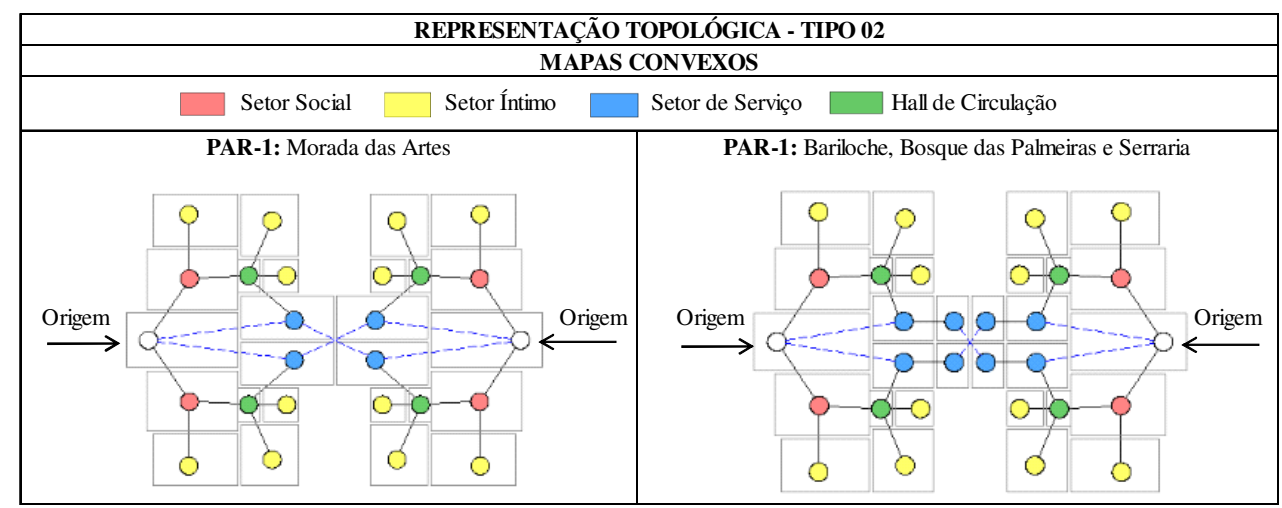

Fonte: Arquivo pessoal do autor 
No projeto do Residencial Morada das Artes, o setor social (sala de estar e jantar) estabelece relação direta com um cômodo do setor íntimo (um dos quartos) e com o hall de circulação interno, sendo esse último responsável por favorecer a interconexão aos demais cômodos. Além disso, a relação de contigüidade com a caixa de escada e hall comum de circulação é instituída tanto pelo setor social quanto pelo setor de serviço. Os demais projetos possuem os setores, social e íntimo, idênticos ao do Residencial Morada das Artes, o único setor distinto é o de serviço que se divide em dois cômodos.

Diferenciando-se dos demais, o projeto do Residencial José Bernardes (Quadro 5) é o único exemplar que não apresenta hall de circulação interno. Deste modo, o acesso aos setores, íntimo e de serviço, são diretamente interligados ao setor social. Já no Residencial Ouro Preto I, o hall de circulação interno é exclusivamente para acesso aos quartos. Assim sendo, o setor social continua estabelecendo contato com dois cômodos.

\section{Quadro 5 - Representação Topológica dos Projetos Tipo 02: projeto dos Residenciais José Bernardes e Ouro Preto I}

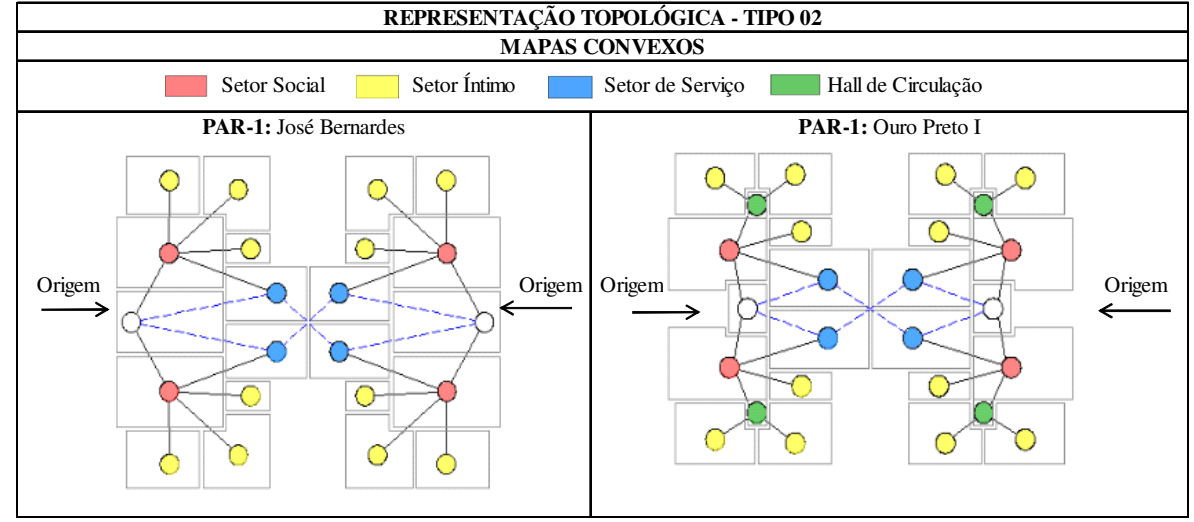

Fonte: Arquivo pessoal do autor

\subsection{Representação Topológica e Caracterização do Tipo 03}

Composto por um único empreendimento, o Residencial Galápagos (PAR-1), o tipo 03 é caracterizado pela existência de uma circulação externa descoberta voltada para o interior do condomínio, constituindo assim um pátio interno de uso comum. Cada caixa de escada possibilita o acesso a duas e/ou quatro unidades habitacionais distribuídas linearmente, em módulos dois a dois. Topologicamente, as relações entre as partes do projeto são estabelecidas pelo setor social que mantém ligação direta com um dos quartos, hall de circulação interna e setor de serviço. Ademais, a maior parte dos cômodos é no formato retangular, exceto os dois quartos idênticos com formato Quadro 6 - Representação Topológica do Projeto Tipo 03

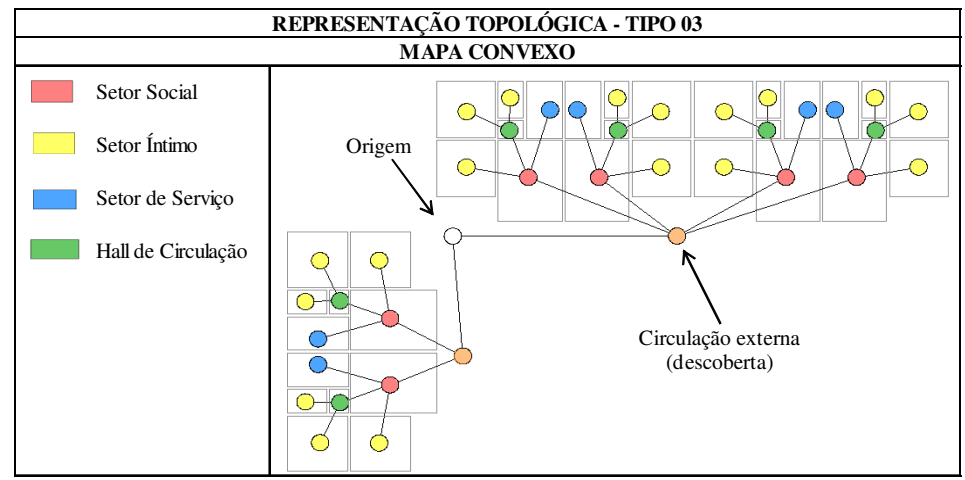

Fonte: Arquivo pessoal do autor quadrado (Quadro 6). 


\section{CONSIDERAÇÕES FINAIS}

As análises evidenciaram que o tradicional modo tripartido de habitação (social, íntimo e serviço) é significativamente presente nos projetos. Identificaram-se três tipos arquitetônicos: (1) blocos em formato "H"; (2) com caixa inserida; e (3) com caixa de escada e circulação externa. As relações topológicas evidenciaram que: dos 14 projetos do tipo 01,11 deles os halls de circulação interna estabelecem conexão com dois ou três cômodos do setor íntimo e com o setor de serviço. Em três projetos o setor de serviço é acessado do setor social e hall de entrada respectivamente; em seis projetos do tipo $02 \mathrm{e}$ no projeto do tipo 03, o setor social é o principal setor da habitação, de modo que o mesmo funciona como cômodo de distribuição para os demais. A presença dos halls de circulação e entrada é inexistente em um dos projetos. Logo, soluções de projetos cuja inserção de halls de distribuição não seja considerada, favorecem a redução de área útil e pode apresentar problemas relacionados à perda de privacidade, visto que quartos e banheiros ficam expostos comumente à sala de estar e jantar.

Alguns projetos foram literalmente repetidos, sem nenhuma modificação de dimensionamento e/ou posicionamento de cômodos. O exemplo mais significativo reserva-se aos projetos do PAR-2, dos seis analisados, apenas um possui projeto diferenciado. Desse modo, os problemas de funcionamento ou inadequação dimensional constatado num desses empreendimentos se estende aos demais.

Contata-se que em Maceió, as Habitações do PAR, assumem um aspecto formal uniformizador e repetitivo. Além disso, a organização espacial interna e a geometria dos cômodos das habitações são, comumente, associados a processos rígidos, sem flexibilidade, e limitados geometricamente por quadriláteros. Essa constatação também possibilitou a identificações das formas geométricas dos setores funcionais que sinalizaram as possíveis facilidades e/ou dificuldades de utilização dos espaços e dos percursos desenvolvidos pelos usuários no interior da habitação. Nesse quesito, destacam-se como pontos positivos os projetos que adotaram formatos em "T" (no setor social) e "L" (nos quartos e cozinha). O uso do formato quadricular, não se demonstrou adequado, sobretudo no banheiro. Assim, espera-se que essa pesquisa possa contribuir com a produção de novos projetos habitacionais com qualidade funcional.

\section{REFERÊNCIAS}

BRANDÃO, Douglas Queiroz; HEINECK, Luiz Fernando Mahlmann. Diversidade de arranjos espaciais de apartamentos no Brasil: duas formas de análise, duas diferentes conclusões. In: XXIV ENCONTRO NACIONAL DE ENGENHARIA DE PRODUÇÃO, 2004., 2004, Florianópolis. Anais... . Florianópolis: ENEGEP, 2004. p. 2775 2782.

CAIXA. Relatório posição PAR em Alagoas. 2009.

HILLIER, Bill; HANSON, Julienne. The social logic of space. Cambridge: Cambridge University Press, 1998.

MINISTÉRIO DAS CIDADES. Medida provisória n. 1823: 29, abril, 1999. Disponível em: <http://www.cidades.gov.br/secretarias-nacionais/secretaria-de-habitacao/programas-e-acoes/par>. Acesso em: 10 abr. 2009.

MONTANER, Josep Maria. A modernidade superada: arquitetura, arte e pensamento do século XX. Barcelona: Gustavo Gili, 2001.

SCHNEIDER, Friederike. Atlas de Plantas: viviendas. 2. ed. Barcelona: Gustavo Gili, 1998.

SPERLING, David Moreno. Entre conceitos, metáforas e operações: convergências da topologia na arquitetura contemporânea. Gestão e Tecnologia de Projetos, São Paulo, v. 3, n. 2, p.24-55, 2008. Disponível em: $<$ http://www.arquitetura.eesc.usp.br/gestaodeprojetos/>. Acesso em: 10 mar. 2011.

SPERLING, David Moreno. Arquiteturas contínuas e topologia: similaridades em processo. Dissertação (Mestrado) - Escola de Engenharia de São Carlos, Universidade de São Paulo, São Carlos, 2003. 